\title{
The Addition of Aluminum Nanoparticles to Polypropylene Increases Its Thermal Stability
}

\author{
Javier Arranz-Andrés ${ }^{\mathrm{a}, *}$, Félix A. López ${ }^{\mathrm{b}}$, Rosario Benavente ${ }^{\mathrm{a}}$ \\ ${ }^{a}$ Instituto de Ciencia y Tecnología de Polímeros (ICTP-CSIC), Juan de la Cierva 3, 28006 Madrid, Spain. \\ ${ }^{b}$ Centro Nacional de Investigaciones Metalúrgicas (CENIM-CSIC), Avda. Gregorio Amo 8, Madrid 28040, \\ Spain.
}

\begin{abstract}
This work reports the thermal degradation kinetics of is otactic polypropylene (iPP) and iPP with incorporated Al nanoparticles. The Friedman, Flynn-Wall-Ozawa (FWO), ASTM E698 and Coats-Redfern methods were used to calculate the activation energy of the samples from thermogravimetric data. The thermal stability of the iPP was improved by the introduction of the nanoparticles: the maximum decomposition temperature of the nanocomposite increased from $453^{\circ} \mathrm{C}$ to $457^{\circ} \mathrm{C}$ and the activation energy from $226 \mathrm{~kJ} / \mathrm{mol}$ to $244 \mathrm{~kJ} / \mathrm{mol}$. The thermal degradation models of iPP can be described by "Contracting Sphere" model, whereas that to nanocomposite by $\mathrm{Rn}(\mathrm{n}=4.8)$ model (phase boundary reaction).
\end{abstract}

Keywords: Polypropylene-Aluminum nanocomposites; Thermal degradation; Kinetics; Reaction model

\section{INTRODUCTION}

Polypropylene (PP) is one of the most important commodity polymers. Its attractive physical and mechanical properties, low price, light weight, and the ease with which it can be processed, have led to its use in different sectors of industry. It is commonly employed in the manufacture of film, fibers and the matrix of polymer composites, but the incorporation of specific fillers allows it to be used in the production of many other products.

Polymer-metal composites are an interesting class of materials that combine the electrical characteristics of metals and the mechanical properties of polymers. They can also be processed following methods typically used for polymers [1]. Currently, there is much interest in the use of metal nanoparticles as advanced additives in the functionalization of plastics, and considerable research efforts are being made in this area [2-6]. Polymer nanocomposites have better physical and mechanical properties than conventional composites based on a polymer matrix with micro-sized fillers. Products made from them include high-energy radiation shielding, microwave absorbers, optical limiters, polarizers, sensors, and hydrogen storage systems. In addition to their intrinsic nanoscopic properties, these materials are of interest since changes in the fillermatrix interface area alters their glass transition temperature, crystallinity, free volume content and thermal stability, allowing materials to be produced that may have novel applications. Increasing the temperature during the processing stage to compensate for the increase in viscosity produced by the incorporation of the fillers may, however, change the thermal degradation characteristics of the material.

The thermal behavior of a poly mer can be adjusted to meet required specifications if its thermal degradation kinetics are known. Pyrolysis is the standard technique used to study the thermal behavior of polymers, and much interest has been shown in discovering more about the thermal degradation of PP [7-12] and its nanocomposites. Thermogravimetric analysis (TGA) can be used to obtain the associated apparent activation energy $\left(E_{a}\right)$ and kinetic model of decomposition [7, 11, 13]. Variables such as the pre-exponential factor $(A)$, reaction order, and the $E_{a}$ can be calculated from the TGA curve.

Several studies have examined the degradation features of polymer nanocomposites [14-18] but only a few have dealt with the thermal degradation kinetics of PP nanocomposites that incorporate metal particles $[19,20]$. The present work examines the thermal stability of pure PP and $\mathrm{PP} / \mathrm{Al}$ nanocomposites in an $\mathrm{N}_{2}$ atmosphere using TGA. The Fried man, Flynn-Wall-Ozawa (FW O), ASTM E698 and Coats-Redfern methods were used to calculate the $E_{a}$ of the samples from the TGA data.

\section{MATERIALS AND METHODS} 2.1. Materials

The polymeric matrix used in the present work was a commercially available, metallocenecatalyzed, isotactic PP (iPP; Metocene HM562P: melt flow index $15 \mathrm{~g} / 10 \mathrm{~min}$, ISO 1133), kindly supplied by LyondellBasell. The Al nanoparticles 
(average diameter $18 \mathrm{~nm}$ ) were purchased from IOLITEC.

\section{2. (Na no) composite film preparation}

A PP composite with an Al nanoparticle content of 5\% (by volume) (PPA15) was prepared via melt processing $\left(165^{\circ} \mathrm{C}, 120 \mathrm{rpm}\right.$ for $\left.40 \mathrm{~min}\right)$ in a Haake Minilab (Thermo Electron Corporation) twin-screw extruder (capacity $7 \mathrm{~cm}^{3}$ ) with corotating conical screws. After extrusion of the nanocomposite, a $250 \square$ mthick film was prepared by its compression in a Collin press $\left(190^{\circ} \mathrm{C}, 10\right.$ $\mathrm{MPa}, 6 \mathrm{~min})$. The film was then rapidly cooled (80 ${ }^{\circ} \mathrm{C} \min ^{-1}$ ) by the press' cooling plates. The same procedure used to produce iPP without Al nanoparticles as a control.

\subsection{Scanning electron microscopy (SEM)}

Samples of the iPP and PPA15 films were cryofractured and observations made using an XL30 ESEM PHILIPS scanning electron microscope (SEM).

\subsection{Thermogravimetric analysis}

The thermal stability measurements of the samples was examined by TGA using a TA Q500 thermogravimetric analyzer over the temperature range $20-800{ }^{\circ} \mathrm{C}$ in an $\mathrm{N}_{2}$ atmosphere. Kinetic analyses were performed using heating ramps of 2 , $5,10,20$ and $30{ }^{\circ} \mathrm{C} / \mathrm{min}$. Continuous recordings of sample temperature, sample weight and heat flow were recorded.

\section{THEORY/CALCULATION}

\subsection{Mathematical models for determining thermal kinetics}

In polymer decomposition it is generally assumed that the degree of conversion is proportional to the concentration (wt\%) of the reacted material [21]. The degree of conversion can be expressed by the following basic rate equation (1):

$$
\frac{d \alpha}{d t}=\beta \frac{d \alpha}{d T}=k(T) . f(\alpha)
$$

where $\alpha$ is the degree of conversion, $\beta$ is the heating rate, and $f(\alpha)$ and $k(T)$ are functions of conversion and temperature respectively. $\alpha$ is calculated in terms of mass loss according to equation (2):

$$
\alpha=\frac{w_{0}-w_{t}}{w_{0}-w_{f}}
$$

where $\mathrm{w}_{0}, \mathrm{w}_{\mathrm{t}}$ and $\mathrm{w}_{\mathrm{f}}$ are the mass of the sample at the beginning of the decomposition process at any chosen point in the TGA curve, and the final mass respectively. $k(T)$ is the temperature, which is dependent on the rate of heat flow; this is often modeled successfully by the Arrhenius equation (3):

$$
k(T)=A e^{-E / R T}
$$

where $E(\mathrm{~kJ} / \mathrm{mol})$ is the activation energy, $A\left(\mathrm{~min}^{-1}\right)$ the pre-exponential factor, and $R(8.314 \mathrm{~J} / \mathrm{mol} . \mathrm{K})$ the gas constant. By combining equations (1) and (3), the reaction rate can be written as:

$$
\frac{d \alpha}{d t}=A e^{-E / R T} f(\alpha)
$$

\subsubsection{Friedman method}

The Friedman method of determining thermal kinetics [22] is based on the Arrhenius equation and takes into account the logarithm of the conversion rate $(d \alpha / d t)$ as a function of the reciprocal of the temperature $(1 / T)$ for different degrees of conversion $\alpha$, according to Equation (5):

$\left.\ln \frac{d \alpha}{d t}\right|_{\alpha i}=\ln \left(A_{i} f\left(\alpha_{i, j}\right)\right)-\frac{E_{a i}}{R \cdot T_{i, j}}$

where $i$ is the index of conversion, $j$ is the curve index, $E_{a}$ the apparent activation energy at $\alpha_{i}$, and $f\left(\alpha_{i, j}\right)$ the function dependent on the reaction model (assumed to be constant for a given reaction progress $\alpha_{i, j}$ for all curves $j$ ). Since $f(\alpha)$ is constant at each degree of conversion $\alpha i$, the curve for the logarith $\mathrm{m}$ of the reaction rate vs. $1 / T$ is linear, with a slope of $E_{a} / R$. The intercept is $A$.

\subsubsection{Flynn-Wall-Ozawa method}

The FWO method [23,24] is derived from the integral isoconversional method. Using Doyle's approximation [25], the reaction rate, in logarith mic form, can be expressed as:

$\ln \beta=\ln \left(\frac{A E_{a}}{R \cdot g(\alpha)}\right)-5.331-1.052 \frac{E}{R} \frac{1}{T}$

where $\beta$ is the heating rate and $g(\alpha)$ the conversion function. Thus, for any constant $\alpha$ value, the plot $\ln \beta$ vs. $1 / T$ recorded at should be a straight line irrespective of the heating rate. The $E_{a}$ can be determined from the slope.

\subsubsection{ASTM E698}

The ASTM E698 method [26] is based on the assumption that the maximum temperature (for example of the derivative thermogravimetric [DTG] curve) of a single step reaction is reached at the same degree of conversion irrespective of the heating rate. Although this assumption is only partly true, the resulting error is small. In this method, the logarithm of the heating rate is plotted against the reciprocal maximum temperature. The slope of the yielded straight line is proportional to the $E_{a}$, just as in the FOW method:

$\ln \left(\frac{\beta}{T}\right)=\ln A+\ln (1-\alpha)+\frac{E}{R} \frac{1}{T}$ 


\subsubsection{Coats-Redfern method}

The Coats-Redfern method [27] provides the thermal decomposition mechanism from the mass loss. An asymptotic approximation of $2 \mathrm{RT}^{\mathrm{E}} \mathrm{E}_{\mathrm{a}}<1$ for the resolution of Equation (8):

$$
g(\alpha)=\int_{0}^{\alpha} \frac{d \alpha}{f(\alpha)}=\frac{A}{\beta} \int_{T o}^{T} \exp \left(-\frac{E_{a}}{R T}\right) d T=\frac{A E_{a}}{\beta R} p\left(\frac{E_{a}}{R T}\right)
$$$$
\ln \frac{g(\alpha)}{T^{2}}=\ln \frac{A R}{\beta E}-\frac{E}{R T}
$$

This method is one of the most widely used for the determination of reaction processes. The $E_{a}$ at a constant heating rate for any of the $g(\alpha)$ functions listed in Table 1 can be obtained from Equation (9).

allows Equation (9) to be obtained:

Table 1. Functions of the most common reaction mechanis ms

\begin{tabular}{|c|c|c|c|c|}
\hline Name of the function & Symbol & $f(\alpha)$ & $g(\alpha)$ & $\begin{array}{l}\text { Rate-determining } \\
\text { mechanism }\end{array}$ \\
\hline \multicolumn{5}{|l|}{$\begin{array}{l}\text { Sigmoidal rate equations or random } \\
\text { nucleation and subsequent growth }\end{array}$} \\
\hline Avrami-Erofeev equation & $\mathrm{A}_{3 / 2}$ & $(3 / 2)(1-\alpha)[-\ln (1-\alpha)]^{1 / 3}$ & {$[-\ln (1-\alpha)]^{2 / 3}$} & Assumed random nucleation \\
\hline Avrami-Erofeev equation & $\mathrm{A}_{2}$ & $2(1-\alpha)[-\ln (1-\alpha)]^{1 / 2}$ & {$[-\ln (1-\alpha)]^{1 / 2}$} & and subsequent growth \\
\hline Avrami-Erofeev equation & $A_{n}$ & $\mathrm{n}(1-\alpha)[-\ln (1-\alpha)]^{(1-1 / n)}$ & {$[-\ln (1-\alpha)]^{(1-1 / n)}$} & \\
\hline Autocatalytic & & $(1-\alpha)^{n} \alpha^{m}$ & & \\
\hline \multicolumn{5}{|l|}{ Chemical process or mechanism } \\
\hline First order & $\mathrm{F}_{1}$ & $(1-\alpha)$ & $-\ln (1-\alpha)$ & Chemical reaction \\
\hline Second order & $\mathrm{F}_{2}$ & $(1-\alpha)^{2}$ & $(1-\alpha)^{-1}-1$ & Chemical reaction \\
\hline Third order & $\mathrm{F}_{3}$ & $(1 / 2)(1-\alpha)^{3}$ & $(1-\alpha)^{-2}-1$ & Chemical reaction \\
\hline \multicolumn{5}{|l|}{ Phase boundary reaction } \\
\hline Power law & $\mathrm{R}_{1}$ & $(1-\alpha)^{0}$ & $\alpha$ & Contracting disk \\
\hline Power law & $\mathrm{R}_{2}$ & $2(1-\alpha)^{1 / 2}$ & $1-(1-\alpha)^{1 / 2}$ & Contracting cylinder \\
\hline Power law & $\mathrm{R}_{3}$ & $3(1-\alpha)^{2 / 3}$ & $1-(1-\alpha)^{1 / 3}$ & Contracting sphere \\
\hline \multicolumn{5}{|l|}{ Acceleration rate equations } \\
\hline Mampel power law & $\mathrm{P}_{1 / 2}$ & $2 \alpha^{1 / 2}$ & $\alpha^{1 / 2}$ & Nucleation \\
\hline Mampel power law & $\mathrm{P}_{1 / 3}$ & $3 \alpha^{2 / 3}$ & $\alpha^{1 / 3}$ & Nucleation \\
\hline Mampel power law & $\mathrm{P}_{1 / 4}$ & $4 \alpha^{3 / 4}$ & $\alpha^{1 / 4}$ & Nucleation \\
\hline \multicolumn{5}{|l|}{ Based on the diffusion mechanism } \\
\hline Parabola low & $\mathrm{D}_{1}$ & $1 / 2 \alpha$ & $\alpha^{2}$ & One-dimensional diffusion \\
\hline Valensi equation & $\mathrm{D}_{2}$ & {$[-\ln (1-\alpha)]^{-1}$} & {$[(1-\alpha) \ln (1-\alpha)]+\alpha$} & Two-dimensional diffusion \\
\hline Jander equation & $\mathrm{D}_{3}$ & $(3 / 2)(1-\alpha)^{(2 / 3)}\left[1-(1-\alpha)^{(1 / 3)}\right]^{-1}$ & {$\left[1-(1-\alpha)^{1 / 3}\right]^{2}$} & $\begin{array}{l}\text { Three-dimensional diffusion } \\
\text { Spherical symmetry }\end{array}$ \\
\hline Ginstling-Brounstein equation & $\mathrm{D}_{4}$ & $(3 / 2)\left[(1-\alpha)^{-1 / 3}-1\right]^{-1}$ & $1-(2 \alpha / 3)-(1-\alpha)^{2 / 3}$ & $\begin{array}{l}\text { Three-dimensional diffusion, } \\
\text { cylindrical symmetry }\end{array}$ \\
\hline
\end{tabular}

\section{RESULTS AND DISCUSSION}

Figure 1 shows the good dispersion and distribution of the Al nanoparticles within the iPP matrix. No large agglomerations of $\mathrm{Al}$ nanoparticles were observed.

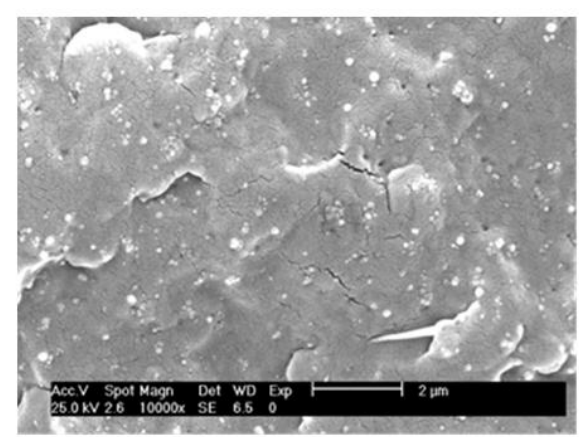

Figure 1. SEM photomicrograph of PPA15

\subsection{Thermal degradation of $i P P$ and PPAl5}

Figures 2 and 3 show the TGA and DTG curves for the iPP and PPAl5 treated at the different heating rates $\left(2,5,10,20\right.$ and $\left.30^{\circ} \mathrm{C} / \mathrm{min}\right)$. All the associated TGA curves showed single-step decomposition. The DTG curves for both materials showed a single decomposition peak between 427 and $470{ }^{\circ} \mathrm{C}$ for the iPP, and between $432-475^{\circ} \mathrm{C}$ for the PPA15. Table 2 shows the maximum decomposition temperatures $\left(\mathrm{T}_{\mathrm{m}}\right)$ determined from the DGT curves for both materials, and the mass losses at the different heating rates. The decomposition of iPP and PPA15 is due to the breakdown of the polymer chains. The TGA curves shifted towards higher temperatures with increasing heating rate. 

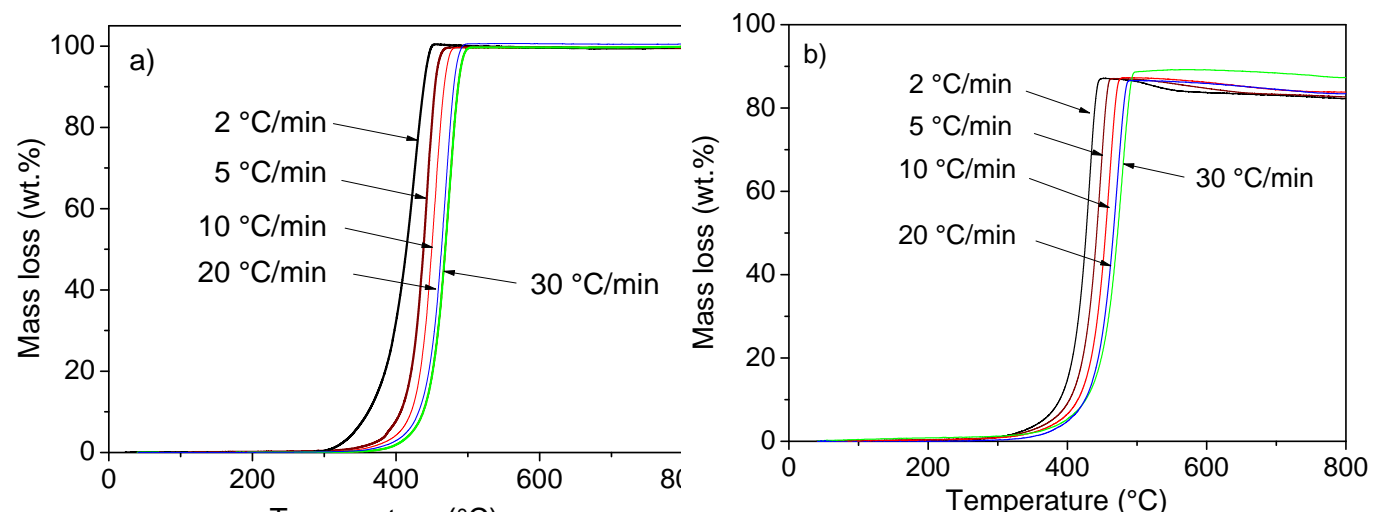

Figure 2. TGA curves for the decomposition of a) iPP and b) PPAl5 at different heating rates.
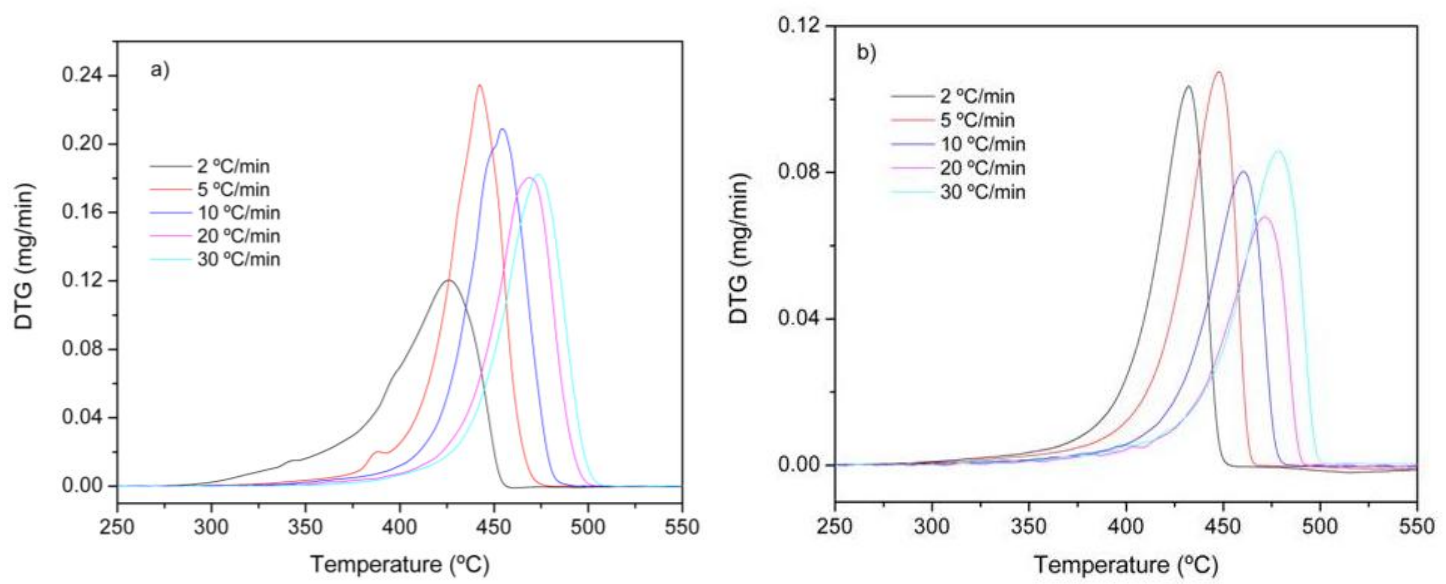

Figure 3. DTG curves for the decomposition of a) iPP and b) PPAl5 at different heating rates.

An increase was seen in the $T_{m}$ with increasing heating rate. This effect has been described in other studies on the thermal decomposition of polymers [28] and may be the result of thermal hysteresis. Table 2 shows that the presence of the Al nanoparticles to be associated with a shift of $\mathrm{T}_{\mathrm{m}}$ towards higher values; the thermal stability for the iPP was, therefore, improved. At all the heating rates used, the $T_{m}$ of the PPA 15 was some $4{ }^{\circ} \mathrm{C}$ higher than that of the iPP (mean $457.2 \pm 2{ }^{\circ} \mathrm{C}$ compared to $453.4 \pm 2{ }^{\circ} \mathrm{C}$ ). A similar increase was described by Lee et al. [20] for a PP sample incorporating Pd nanoparticles. FTIR spectra have shown the existence of several interactions between a polyvinylidene fluoride matrix and Al nanoparticles in nanocomposites similar to the present PPA15 [29]. These interactions can affect the mobility of polymer chains and/or modify the $E_{a}$ of the degradation process. A shift to lower wavelengths has also been recorded with increasing $\mathrm{Al}$ content in the FTIR spectra of other PP-Al composites (unpublished).

Table 2. TGA and DTG data for the decomposition of iPP and PPAl5 at different heating rates

\begin{tabular}{|l|l|l|l|l|}
\hline & TGA & DTG & \\
\hline $\begin{array}{l}\beta \\
\left({ }^{\circ} \mathrm{C} / \mathrm{min}\right)\end{array}$ & $\begin{array}{l}\text { iPP } \\
\text { Weight loss } \\
(\text { wt. \% })\end{array}$ & $\begin{array}{l}\text { PPA15 } \\
\text { Weight loss } \\
(\text { wt.\% })\end{array}$ & $\begin{array}{l}\text { iPP } \\
\mathrm{T}_{\mathrm{m}} \\
\left({ }^{\circ} \mathrm{C}\right)\end{array}$ & $\begin{array}{l}\text { PPA15 } \\
\mathrm{T}_{\mathrm{m}} \\
\left({ }^{\circ} \mathrm{C}\right)\end{array}$ \\
\hline 2 & 99.6 & 86.8 & 427.3 & 432.2 \\
\hline 5 & 100 & 88.6 & 443.4 & 447.9 \\
\hline 10 & 99.6 & 88.6 & 455.4 & 460.1 \\
\hline 20 & 99.6 & 88.6 & 468.3 & 470.6 \\
\hline 30 & 99.6 & 88.6 & 472.5 & 475.4 \\
\hline Mean & $99.7 \pm 0.2$ & $88.2 \pm 0.8$ & $453.4 \pm 18$ & $457.2 \pm 18$ \\
\hline
\end{tabular}

( $\mathrm{T}_{\mathrm{m}}$ : maximu $\mathrm{m}$ temperature) 
The thermal stabilizing effect of the Al nanoparticles was also seen in terms of the mass loss. Over the temperature interval $20-800{ }^{\circ} \mathrm{C}$, the mean mass loss for all the heating rates was $99.7 \pm 0.2 \%$ for iPP and $88.2 \pm 0.8 \%$ for PPAl5.
Table 3 shows the conversion values $(\alpha, \%)$ with respect to the heating rate. For a heating rate of 2 ${ }^{\circ} \mathrm{C} / \mathrm{min}$, the $\mathrm{T}_{\mathrm{m}}$ of PPA15 was higher than that of iPP for all conversion values. At heating rates above $2{ }^{\circ} \mathrm{C} / \mathrm{min}$, the $\mathrm{T}_{\mathrm{m}}$ of PPAl5 was below that of iPP.

Table 3. Thermal decomposition in terms of percentage conversion at a heating rate of 2, 5, 10, 20 and 30

${ }^{\circ} \mathrm{C} / \mathrm{min}$, and the corresponding degradation temperature in an $\mathrm{N}_{2}$ atmosphere.

\begin{tabular}{|c|c|c|c|c|c|c|c|c|c|c|}
\hline \multirow{3}{*}{ Conversion (\%) } & \multicolumn{5}{|l|}{$\mathrm{iPP}$} & \multicolumn{5}{|c|}{ PPAI5 } \\
\hline & \multicolumn{5}{|c|}{ Heat ing rate $\left({ }^{\circ} \mathrm{C} / \mathrm{min}\right)$} & \multicolumn{5}{|c|}{ Heating rate $\left({ }^{\circ} \mathrm{C} / \mathrm{min}\right)$} \\
\hline & 2 & 5 & 10 & 20 & 30 & 2 & 5 & 10 & 20 & 30 \\
\hline 5 & 339.4 & 386.5 & 401.4 & 412.0 & 419.7 & 351.6 & 363.5 & 376.6 & 390.9 & 386.2 \\
\hline 10 & 359.7 & 404.9 & 419.8 & 430.4 & 436.9 & 381.0 & 394.9 & 407.1 & 417.5 & 419.2 \\
\hline 15 & 373.6 & 414.6 & 428.1 & 439.4 & 445.3 & 394.2 & 408.6 & 421.0 & 431.0 & 435.0 \\
\hline 20 & 383.9 & 420.6 & 433.3 & 445.2 & 450.6 & 402.0 & 416.7 & 429.1 & 439.1 & 444.2 \\
\hline 30 & 397.2 & 428.3 & 440.3 & 453.0 & 458.2 & 411.6 & 426.5 & 439.0 & 449.3 & 455.6 \\
\hline 40 & 406.4 & 433.4 & 445.3 & 458.9 & 463.8 & 417.8 & 432.9 & 445.6 & 456.1 & 463.0 \\
\hline 50 & 414.0 & 437.9 & 449.4 & 463.0 & 468.4 & 422.5 & 437.7 & 450.6 & 461.5 & 468.5 \\
\hline 60 & 420.3 & 441.9 & 453.3 & 467.1 & 472.5 & 426.4 & 441.7 & 454.7 & 465.8 & 473.1 \\
\hline
\end{tabular}

\subsection{Kinetics}

Table 4 shows the $E_{a}$ of the iPP and PPA15 as determined by the different calculation methods. For the iPP, the $E_{a}$ as determined by the Friedman method was $226 \pm 15 \mathrm{~kJ} / \mathrm{mol}$ (the pre-exponential factor, $A$, was $\left.8.5 \times 10^{15} \mathrm{~min}^{-1}\right), 226 \pm 20 \mathrm{~kJ} / \mathrm{mol}$ as determined by the FWO method, and $226 \mathrm{~kJ} / \mathrm{mol}$ as determined by the ASTM E698 method. These values are similar to those reported in the literature for iPP. Lee et al. (2006) reported a value of $229 \pm$ $13 \mathrm{~kJ} / \mathrm{mol}$ as determined by the Friedman method (with an $A$ value of $6.5 \times 10^{15} \mathrm{~min}^{-1}$ ), and of 228 $\mathrm{kJ} / \mathrm{mol}$ as determined by the Kissinger method For the PPA15, the $E_{a}$ was $244 \pm 4 \mathrm{~kJ} / \mathrm{mol}\left(A=1.6 \times 10^{17}\right.$ $\left.\min ^{-1}\right)$ as determined by the Fried man method, 242 $\pm 4 \mathrm{~kJ} / \mathrm{mol}$ as determined by the FWO method, and $244 \mathrm{~kJ} / \mathrm{mol}$ as determined by the ASTM E698 method. Thus, the $E_{a}$ of the PPA15 was around 15 $\mathrm{kJ} / \mathrm{mol}$ higher than that of the iPP: adding the Al nanoparticles therefore improved the thermal stability of the iPP.

Table 4. Apparent activation energy $\left(E_{a}\right)$ and pre-exponential factor values $(A)$ obtained by the different mathematical methods for determining the thermal kinetics of decomposition, plus the thermal degradation mechanism as determined by the Coats-Redfern method.

\begin{tabular}{|l|l|l|l|l|l|l|l|l|}
\hline & \multicolumn{2}{|l|}{ iPP } & \multicolumn{2}{l|}{ PPA15 } \\
& Fried man & FWO & $\begin{array}{l}\text { ASTM } \\
\text { E698 }\end{array}$ & $\begin{array}{l}\text { Coats- } \\
\text { Redfern }\end{array}$ & Fried man & FWO & $\begin{array}{l}\text { ASTM } \\
\text { E698 }\end{array}$ & $\begin{array}{l}\text { Coats- } \\
\text { Redfern }\end{array}$ \\
\hline $\mathrm{E}_{\mathrm{a}}(\mathrm{kJ} / \mathrm{mol})$ & $226 \pm 15$ & $226 \pm 20$ & 226 & 206 & $244 \pm 4$ & $242 \pm 4$ & 244 & 231 \\
$\mathrm{~A}\left(\mathrm{~s}^{-1}\right)$ & $1.42 \times 10^{14}$ & - & - & $4.64 \times 10^{12}$ & $2.72 \times 10^{15}$ & - & - & $2.16 \times 10^{14}$ \\
Mechanism & - & - & - & R3 & - & - & - & Rn \\
\hline
\end{tabular}

Figure 4 shows the variation in $E_{a}$ as determined by the Fried man method with respect to the degree of conversion (interval $0<\alpha<1$ ) for both iPP and PPA15. For the iPP, the $E_{a}$ increased with the degree of conversion. The changes in the slope of the $E_{a}$ /conversion value curve suggest that the thermal decomposition of iPP occurs in three stages. The first stage occurs when $\alpha<0.15$, which has a clear associated maximum $E_{a}$ of $185 \mathrm{~kJ} / \mathrm{mol}$ $\left(148 \pm 15 \mathrm{~kJ} / \mathrm{mol}\right.$; slope: $\left.0.66 ; \mathrm{R}^{2}=0.999\right)$. The second stage occurs when $0.15<\alpha<0.55$, with an associated $E_{a}$ of 185 to $243 \mathrm{~kJ} / \mathrm{mol}$ (mean $224 \pm 16$ $\mathrm{kJ} / \mathrm{mol}$; slope: $\left.0.14 ; \mathrm{R}^{2}=0.960\right)$. The third stage occurs when $0.55<\alpha<0.90$, for which the associated $E_{a}$ lies between 245 and $253 \mathrm{~kJ} / \mathrm{mol}$ (mean: $251 \pm 2$ $\mathrm{kJ} / \mathrm{mol}$; slope: $0.021 ; \mathrm{R}^{2}=0.888$ ). A rapid increase in $E_{a}$ for low conversion values has also been reported by Chan and Balke [30]. 


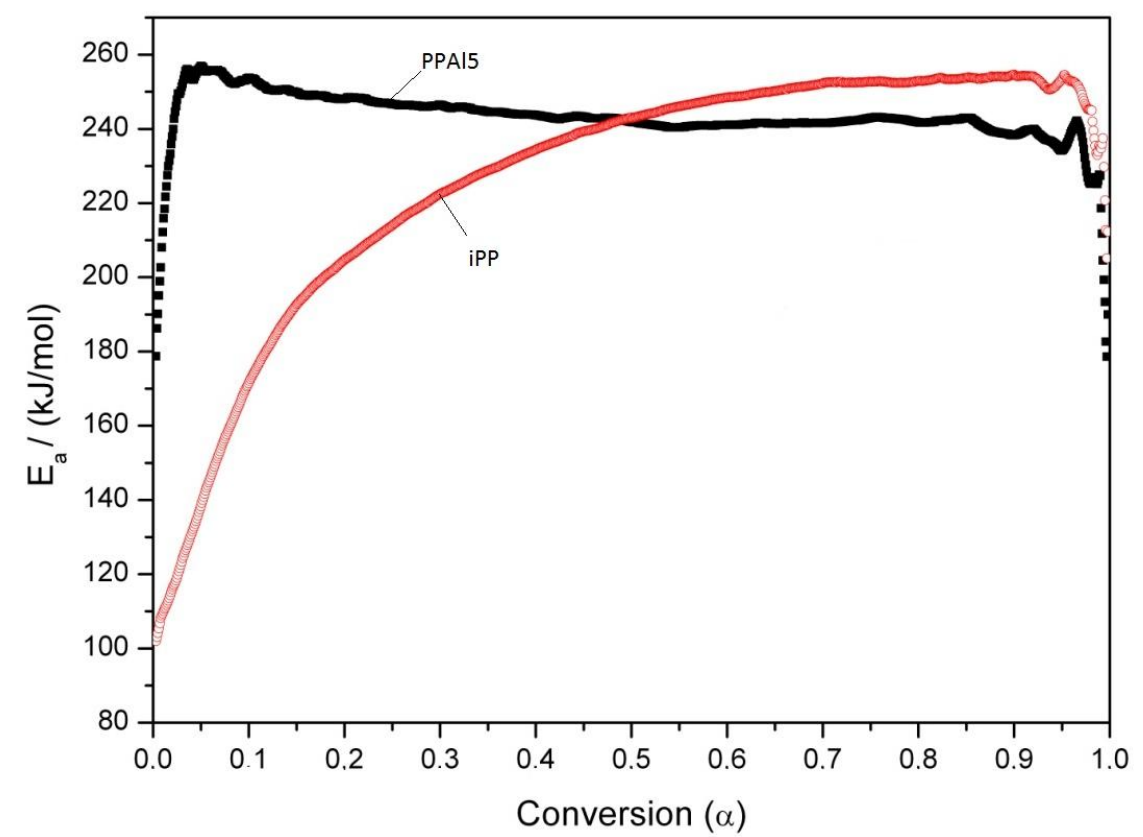

Figure 4. Variation in apparent activation energy as determined by the Fried man method.

For the PPA15, a small increase in $E_{a}$ was seen (from $179 \mathrm{~kJ} / \mathrm{mol}$ to $257 \mathrm{~kJ} / \mathrm{mol}$; mean $238 \pm$ $22 \mathrm{~kJ} / \mathrm{mol}$ ) over the interval $0<\alpha<0.05$. Over the interval $0.05<\alpha<0.95$, it remained practically constant with increasing degree of conversion. These results suggest that the incorporation of the Al nanoparticles produced changes in the thermal decomposition mechanis m of iPP.

Table 4 shows the calculated $E_{a}$ and degradation mechanism of iPP as determined by the Coats-Redfern method. The mean $E_{a}$ for the iPP was $206 \mathrm{~kJ} / \mathrm{mol}$, quite different to the values provided by the other methods. Again, this may be due to the decomposition reaction involving more than one stage and different mechanisms. The thermal degradation mechanism of iPP is proposed to be R3 type (contracting sphere). The mean $E_{a}$ for the PPA15 was approximately $231 \mathrm{~kJ} / \mathrm{mol}$; the reaction mechanism was Rn-type (f $[\alpha]=\mathrm{n}[1-\alpha]^{[1-}$ ${ }^{1 / n]}$, where $\mathrm{n}=4.8$ ).

\section{CONCLUSIONS}

The dynamic degradation of PP and a PPAl nanocomposite material was compared via TGA. The Friedman, Flynn-Wall-Ozawa (FWO), ASTM E698 and Coats-Redfern methods were used to calculate the $E_{a}$ of the samples. The thermal stability for the iPP was improved with the introduction of the Al nanoparticles, showing a shift of the TGA curves towards higher temperatures. The thermal stabilizing effect of the Al nanoparticles was also seen in terms of the mass loss. Over the temperature interval $20-800{ }^{\circ} \mathrm{C}$, the mean mass loss for all the heating rates was $99.7 \pm$ $0.2 \%$ for $\mathrm{iPP}$ and $88.2 \pm 0.8 \%$ for PPAl5.
Moreover, the $E_{a}$ of the PPAl5 was around 15 $\mathrm{kJ} / \mathrm{mol}$ higher than that of the iPP, which means that adding the Al nanoparticles the thermal stability of the iPP is imp roved.

The thermal degradation models of iPP can be described by "Contracting Sphere" model, whereas that to PPAl5 by $\mathrm{Rn}(\mathrm{n}=4.8)$ model (phase boundary reaction).

\section{ACKNOWLEDGMENTS}

This work was funded by the Ministerio de Ciencia e Innovación (project MAT2010-19883) and CYTED Project 311RT0417. J. Arranz-Andrés was supported by a CSIC JAE-Doc Program.

\section{REFERENCES}

[1]. Bhattacharya SK. Metal-Filled Polymers: Properties and Applications. New York: Marcel Dekker; 1986.

[2]. G. Carotenuto LN. Nanocomposites MetalFilled, in the Encyclopedia of Polymer Science and Technology. New York: Wiley; 2003.

[3]. Zapata PA, Tamayo L, Páez M, Cerda E, Azócar I, Rabagliati FM. Nanocomposites based on polyethylene and nanosilver particles produced by metallocenic "in situ" polymerization: Synthesis, characterization, and antimic robial behavior. Eu rop Poly $\mathrm{m}$ J. 2011;47:1541-9.

[4]. Stelzig SH, Menneking C, Hoffmann MS, Eisele K, Barcikowski S, Klapper M, et al. Compatibilization of laser generated antibacterial $\mathrm{Ag}$ - and $\mathrm{Cu}$-nanoparticles for 
perfluorinated implant materials. Europ Poly m J. 2011;47:662-7.

[5]. Pradhan S, Costa FR, Wagenknecht U, Jehnichen D, Bhowmick AK, Heinrich G. Elastomer/LDH nanocomposites: Synthesis and studies on nanoparticle dispersion, mechanical properties and interfacial adhesion. Europ Poly m J. 2008;44:3122-32.

[6]. Alexandrid is P, Tsianou M. Block copolymer-directed metal nanoparticle morphogenesis and organization. Europ Poly m J. 2011;47:569-83.

[7]. Chan JH, Balke ST. The thermal degradation kinetics of polypropylene: Part III. Thermogravimetric analyses. Polym Degrad Stab. 1997;57:135-49.

[8]. Bockhorn H, Hornung A, Hornung U, Schawaller D. Kinetic study on the thermal degradation of polypropylene and polyethylene. J Anal Appl Pyrol. 1999;48:93-109.

[9]. Gao Z, Kaneko T, A masaki I, Nakada M. A kinetic study of thermal degradation of polypropylene. Polym Degrad Stab. 2003;80:269-74.

[10]. Cerruti P, Malinconico M, Rychly J, Matisova-Rychla L, Carfagna C. Effect of natural antioxidants on the stability of polypropylene films. Polym Degrad Stab. 2009;94:2095-100.

[11]. Aboulkas A, El harfi K, El Bouadili A. Thermal degradation behaviors of polyethylene and polypropylene. Part I: Pyrolysis kinetics and mechanis ms. Energ Convers Manage. 2010;51:1363-9.

[12]. Gómez-Elvira JM, Benavente R, Martínez MC. Unravelling the contribution of chain microstructure in the mechanism of the syndiotactic polypropylene pyrolysis. Polym Degrad Stab. 2013;98:1150-1163.

[13]. Budrugeac P. Evaluation of the nonis othermal kinetic parameters of the thermal and thermo-oxidative degradation of polymers and polymeric materials: Its use and abuse. Polym Degrad Stab. 2000;71:185-7.

[14]. Pandey JK, Raghunatha Reddy K, Pratheep Kumar A, Singh RP. An overview on the degradability of polymer nanocomposites. Poly m Degrad Stab. 2005;88:234-50.

[15]. Lecouvet B, Bourbigot S, Sclavons $M$, Bailly C. Kinetics of the thermal and thermo-oxidative degradation of polypropylene/halloysite nanocomposites. Poly m Degrad Stab. 2012;97:1745-54.

[16]. Fereidoon A, Hemmati M, Kordani N, Kameli M, Ahangari MG, Sharifi N. The effect of acid-treatment of carbon nanotubes on the thermal kinetics of isotactic polypropylene. J Macromol Sci, B. 2009;50:665-78.

[17]. Rakhimkulov AD, Lomakin SM, Dubnikova IL, Shchegolikhin AN, Davidov EY, Kozlowski R. The effect of multi-walled carbon nanotubes addition on the thermooxidative decomposition and flammability of PP/MWCNT nanocomposites. J Mater Sci. 2010;45:633-40.

[18]. Palacios J, Perera R, Rosales C, Albano C, Pastor JM. Thermal degradation kinetics of PP/OMMT nanocomposites with $\mathrm{mPE}$ and EVA. Poly m Degrad Stab. 2012;97:729-37.

[19]. Day M, Cooney JD, Mackinnon M. Degradation of contaminated plastics: a kinetic study. Polym Degrad Stab. 1995;48:341-9.

[20]. Lee JY, Liao Y, Nagahata R, Horiuchi S. Effect of metal nanoparticles on thermal stabilization of polymer/metal nanocomposites prepared by a one-step dry process. Poly mer. 2006; 47:7970-9.

[21]. Mohoriè I, Krajnc M, Šebenikb U. Modelfree Kinetics Analysis of Thermal Degradation of Polysiloxane Lubricant. Chem Biochem Eng Q, 2009;23:493-496.

[22]. Friedman, HL, Kinetics of thermal degradation of char-forming plastics from thermogravimetry. Application to a phenolic plastic, J Poly m Sci C, 1964;6: 183-195.

[23]. Flynn J, Wall L, A quick, direct method for the determination of activation energy from thermogravimetric data. J Poly m Sci Poly m Lett, 1966;4:4323-328

[24]. Ozawa A. New method of analyzing thermogravimetric data. B Chem Soc JPN, 1965;38:1881-1886.

[25]. Doyle C. Kinetic analysis of thermogravimetric data. J Appl Polym Sci, 1961;5:285-292.

[26]. ASTM E698, “Arrhenius Kinetic Constants for Thermally Unstable Materials", ASTM International, West Conshohocken, PA

[27]. Coats AW, Redfern JP. Kinetic parameters from thermogravimetric data. Nature, 1964;201:68-69.

[28]. Zheng P, Ling XK. A thermal degradation mechanis $m$ of polyvinyl alcohol/silica nanocomposites. Polym Degrad Stab, 2007;92:1061-71.

[29]. Arranz-Andrés J, Pulido-González N, Fonseca C, Pérez E, Cerrada ML. Lightweight nanocomposites based on poly(vinylidene fluoride) and Al nanoparticles: Structural, thermal and mechanical characterization and EMI 
shielding capability. Mat Chem Phys, 2013; 142:469-478

[30]. Chan JH, Balke ST. The thermal degradation kinetics of polypropylene: Part III. Thermogravimetric Analyses. Polym Degrad Stab, 1997;57:135-149. 